\title{
ROBERTO BOLAÑO: PENSAR A LA MUJER ENTRE LA CONDICIÓN DIÁDICA Y EL ESPACIO GEOMÉTRICO
}

\author{
Nelida Sánchez Ramos ${ }^{1}$ \\ Universidad de Colima, México
}

\begin{abstract}
Resumen: En el presente trabajo se hace una inscripción crítica sobre la mujer en el espacio a partir de cuatro obras fundamentales de Roberto Bolaño - Los detectives salvajes (1998), Amuleto (1999), Putas asesinas (2001) y 2666 (2003) -, en éstas se analizan los conceptos de espacio de la realidad y tiempo que se presentan en la narración literaria. Previamente a la perspectiva ofrecida por Roberto Bolaño se encuentra la visión del filósofo alemán Peter Sloterdijk, quien reflexiona sobre las relaciones y circunstancias mundanas espaciales a través del concepto del poshumanismo. El objetivo es reconstruir la crítica de la ciudad literaria y trazar los posibles horizontes a través de una interpretación filosófica en torno a la exposición de los iconos femeninos; es decir, la voz de la mujer en la época de la ciudad industrial que estalla en el Capitalismo gore, propuesto por Sayak Valencia, ramificaciones con la intimidad, de la violencia y de los contornos urbanos en necrosis. Algo comparable en geometría con las figuras gráciles y sencillas como los círculos, y en este caso la esfera. Esas voces que a priori se pierden entre la inmensidad del capitalismo, la opresión masculina, y se conciertan con la sensación de vacío. La vacuidad de las esferas que ruedan sin parar a través de las palabras que otros narran en un mundo cambiante. En el presente trabajo se procederá a contraponer esa asociación entre la voz femenina y la geometría bolañiana más simple y compleja: lo diádico y el espacio Gore.
\end{abstract}

Palabras clave: Capitalismo; espacio; mujer; poshumanismo; tiempo.

Recibido: 24 de julio de 2019

Aprobado: 28 de octubre de 2019

\footnotetext{
${ }^{1}$ Doctora en Letras españolas e Hispanoamericanas por la Universidad de Salamanca, España, actualmente es Candidata en El Sistema Nacional de Investigadores. Sus áreas de investigación son sociología de la cultura, filosofía del pensamiento, poesía y narrativa chilena de la segunda parte del siglo XX. Correo electrónico: sanchez_nelida@ucol.mx
} 
NeLIDA SÁNCHEZ RAmos

\title{
Roberto Bolaño: thinking of women between the dyadic condition and the geometric space
}

\begin{abstract}
In this paper, a critical inscription is made about women in space, based on four fundamental works by Roberto Bolaño - Los detectives salvajes (1998), Amuleto (1999), Putas asesinas (2001) and 2666 (2003) - , in these analyze the concepts of space of reality and time that are presented in the literary narrative. Prior to the perspective offered by Roberto Bolaño is the vision of the german philosopher Peter Sloterdijk, who reflects on spatial worldly relations and circumstances through the concept of posthumanism. The objective is to reconstruct the criticism of the literary city and trace the possible horizons through a philosophical interpretation around the exposure of the feminine icons; that is, the voice of women at the time of the industrial city that explodes in Gore Capitalism, proposed by Sayak Valencia, ramifications with intimacy, violence and urban contours in necrosis. Something comparable in geometry with graceful and simple figures such as circles, and in this case the sphere. Those voices that a priori are lost among the immensity of capitalism, male oppression, and are constricted with the feeling of emptiness. The emptiness of the spheres that roll without stopping through the words that others narrate in a changing world. In this work we will proceed to contrast that association between the feminine voice and the simplest and most complex bolañian geometry: the dyadic and the Gore space.
\end{abstract}

Keywords: Capitalism; posthumanism; space; time; woman.

\section{Introducción}

El itinerario literario en Roberto Bolaño debe recapitularse a partir de los datos esenciales acerca de la ciudad y de los lugares de la acción que aparecen en las descripciones narratológicas de los personajes, los cuales son los intermediarios de la clase media, así como del torbellino interior que se agolpa y se exterioriza en la obra del autor chileno. Además, en una segunda instancia, y más allá de las referencias concretas que se desprenden en las descripciones de nuestro escritor, la denominada posmodernidad añade el sentido del lugar que se circunscribe en las narraciones. El título genérico de la crítica literaria ha disertado sobre una gastada patología del mal, esta relación la podemos ver en críticas literarias, tales como Patricia Poblete, en conjunto de otras estudiosas de la obra de Bolaño, Celina Manzoni y Daniuska González, quienes rescatan la fascinación por el mal en Bolaño, como un absoluto en su 
narrativa que evoluciona en la ciudad y, especialmente, en el espacio hasta aparecer de forma progresiva como un escenario. Entonces corresponde en primera instancia examinar dicha taxonomía bolañiana, con relación al concepto de espacio que desemboca en la ciudad.

Para empezar, vale la pena hacer un recorrido por el concepto poshumanismo desde el pensamiento filosófico del alemán Peter Sloterdijk, ya que propone que el hombre, y no solo el contemporáneo, quien debe estar en sintonía con las herramientas tecnológicas que faciliten el pensamiento metahumano. Si la posmodernidad abre tiempos duros, se necesita reestrenar un escenario en donde el mundo circunscriba una interpretación humanista, es decir, el hombre enfocado desde un punto de vista geométrico, en donde no se trata de una figura plana, sino poliédrico: máquinas, flora, y fauna en una constante simbiosis para evitar así la modernización del engaño, de la simulación; en pocas palabras, la situación que envió al hombre al vacío en nuestra civilización occidental. Proponemos como ejemplo metodológico comparar dos conceptos fundamentales; primero, el vacío, desde la noción sociológica lipovetskiana del individualismo, y segundo; la esfera, al ser el primer "espacio vivido y vivenciado. Vivimos siempre en espacios, esferas, atmósferas; la experiencia del espacio es la experiencia primaria del existir" (Sloterdijk, Esfera I... 3).

El primer espacio de análisis, preocupaciones y argumentos se da con la pugna de la modernidad. Recapitulemos, la transición del nuevo mundo hacia la modernidad incorporó al continente latinoamericano en las dinámicas económicas y sociales provocadas por las potencias europeas, pero hubo un cierto rezago puesto que ésta solo se hizo visible en las grandes urbes. Las megalópolis que se encuentran siempre en la narrativa bolañiana, son la claridad con lo cercano. Los talentos creadores del mundo europeo - que no se encontraban comprimidos en la tradición y mucho menos occidentalizados - tuvieron el trabajo de descubrir, exteriorizar y representar la realidad contemporánea de sus pueblos mediante el realismo. Sin embargo, la novedad más interesante en el panorama cultural en la clase media fue el extraordinario desarrollo de la novela policiaca —el pensamiento de Bolaño es siempre de 
naturaleza detectivesca y dirigido hacia la clase media-; su estilo tiene la impronta de la novela negra, asociada a la aventura policiaca.

Aunque la novela policiaca haya sido menospreciada a mediados del siglo XX por la historia de la literatura nacional, ya que carecía del toque "nacionalista", no reflexionaba sobre lo mexicano, y se le acusó de cavilar sobre los modelos literarios importados desde Estados Unidos, existe un hito germinal a partir de, "por lo menos hasta que el noir de los setenta introdujo un nuevo espíritu de denuncia y autores más reconocidos" (Picatto 2). El asesinato, el detective y la aventura policiaca tuvieron un nuevo fulgor, también en Bolaño, quien la rejuveneció en la última parte del siglo XX. Por tanto, este género es el conductor, la apropiación subjetiva de la espumidificación sloterdijkeana que transporta desde la superficie narrativa el líquido sustancial del espacio en Bolaño, es decir, el autor chileno entiende que el mundo ha dejado de tener la forma de globo, y el espacio representado, tiene actualmente representación de espuma, puesto que concentra irregularidades que harán que el mundo comience a presentar dificultades: el espacio como no-fondo, el espacio destructor y conformador de esferas; y por último, el espacio globalizado, que no es otra cosa más que la guerra extendida de las espumas. Potencialmente, hacia una definición fenomenológica de los personajes hay que partir por entender que son esferas débiles, yoes sin extensión que adolecen en la gran burbuja de la modernidad.

En suma, el presente trabajo ofrece posibilidades e hipótesis para una autointegración, en donde el vacío proviene de las esferas de la humanidad, entendiéndose, en primera instancia, dentro de dicha intimidad espacial, "Esferas son creaciones espaciales sistémicoinmunológicamente efectivas, para seres estáticos en los que opera el exterior" (Sloterdijk, Esferas I... 16), y se mueven en círculos globulares llamados espumas. Con esto, habría que comenzar y referirnos a Llamadas telefónicas, que es el germen de la conjetura trabajada, e hipotexto de nuestro corpus. En consecuencia, la mujer como una enorme esfera a la que todo le sucede, nada es justo para ella, y estalla ante la violencia del cínico ardid del heteropatriarcado. Esta obra con catorce cuentos reúne la tragedia de los personajes extraviados, los protagonistas detectives, pero sobre todo, incorpora el ícono de la mujer aguerrida. Recordemos 
que, la diégesis está dividida en tres partes: "Llamadas telefónicas" (aventuras literarias de personajes-escritores), "Detectives" (cuentos con hito detectivesco) y "Vida de Anne Moore" (Mujeres de extremada fortaleza). Si bien, la letanía del ser es construida bajo el escenario mexicano en las dos primeras partes, lo cual resulta como un pasado inmediato que originará Los detectives salvajes (1999). Sin embargo, es "Vida de Anne Moore" y sus cuatro relatos, quienes rompen la estructura cadenciosa: el espacio, los protagonistas hipertextuales/ efigies fractales y la mujer como intérprete suprema y cuya instancia consiste en separar su naturaleza en contra del horror. Es aquí donde, lo femenino aparece al final, a través de elementos cinematográficos ${ }^{2}$; es decir, Bolaño ayudado por la cinematografía mexicana — según Bolaño, el nuevo cine erótico mexicano o el nuevo cine de terror mexicano, son lo mismo-, explorará el hardcore y el snuff, subgéneros que extrapola en Putas asesinas y 2666, para sobrevalorar lo que existe en el ser humano: la cosificación femenina mediante atributos del poder sexual.

En vista de lo anterior, y con base en el análisis sociológico y filosófico, este artículo elabora dos ejercicios de lectura: pensar la mujer como esfera del individualismo, y de la ciudad como esferas agrandadas que rasgan al individuo por dentro, desde el útero. Llama a la obra Esferas I: Burbujas. Microsferología, puesto que "lo que ante todo describe es la salida de los vivientes de los regazos maternos reales y virtuales a los cosmos impermeables de las grandes culturas regionales y, más allá de éstas, a los mundos-espuma descentrados y permeables de la cultura global moderna" (Sloterdijk 32). Bolaño sostiene la visión del mundo globalizado y el proceso de transformación de la urbe. Características que son condicionadas por las figuras masculinas, el escritor ve el rompimiento del mundo desde la figura de la contemplación como un simple cinéfilo.

\footnotetext{
${ }^{2}$ Nos interesa rescatar de qué manera se realiza el encuentro entre las imágenes femeninas bajo un definido contexto cinematográfico. Gilles Lipovetsky, en su libro titulado La era del vacio (1986), define las características de la posmodernidad, entre las que destaca la inserción de la cultura porno (que inicia en la década de los 80 ), y en donde hace referencia a la era consumista que sentará lógicas duales con una alta conexión con antinomias. En efecto, el feminismo, la pornografía y la liberación sexual apuntalaron hacia una globalización en donde se aceptó una nueva época indolente, carente de emociones y sin relaciones afectivas.
} 


\section{De Putas asesinadas a Putas asesinas y viceversa}

Asimismo, el siglo XX cierra con la revolución social (1945-1990) y por ende, con original sueño sedicioso de transformar las relaciones entre ambos sexos y modificar a las instituciones y hábitos que encarnaban la vieja dominación masculina. Por su parte, la nueva escisión existente a principios del siglo tuvo sus recompensas. De modo que, la función de la centuria fue la de regular la convivencia entre hombres y mujeres en una sociedad regida por la realización personal del hombre, en donde hasta finales del siglo XIX, la mujer no poseía un lugar en la esfera social. Solo mantenía el papel idealizado y sacralizado para engrandecer al varón, o de una veneración mística que ejerció el poeta romántico en dicho siglo. Hay que tener en cuenta a la mujer arquetipo, diosa, animal y musa, puesto que, "El poeta clásico, por mucho talento o ingenio que tenga, no pasa la prueba porque pretende ser el amo de la Diosa; ella es su ama solamente en el sentido despectivo de quien vive en ociosidad coquetona bajo su protección" (Graves 16). En pocas palabras, queda patente que la lucha de las mujeres, mediante la escritura, como claro ejemplo de caso puntual en la narrativa de Bolaño, reflejada en 2666, se ejerce un poder real hacia mujeres inteligentes y activas laboralmente, es decir, la mujer indeterminada o posmujer fatal (Lipovetsky, La tercera mujer 160). Al mismo tiempo, se despliega una violencia extrema en contra de ellas, la cual tendrá como desenlace diversos feminicidios ${ }^{3}$ dentro de la novela. La ciudad de Santa Teresa se nos presenta como símbolo imperante del machismo y la corrupción en América Latina. Teniendo una clara conciencia desde la ciudad literaria como procedencia de la mujer cosificada, hace posible extrapolar dicha estructura de sometimiento, pues según la tesis de Capitalismo Gore (Valencia 66), vislumbramos una trayectoria femenina: "Cuerpos concebidos como productos de intercambio que alteran y rompen las lógicas del proceso de producción del capital, ya que subvierten los términos de éste al sacar del juego la fase de producción de la mercancía"

${ }^{3}$ En consecuencia, México se ha convertido en una enorme Ciudad Juárez. La información que el periodista Sergio González Rodríguez proporcionó a Bolaño para escribir 2666, tan solo esbozaría a los pequeños demonios que se fortalecerían en la última década, puesto que siete mexicanas son aniquiladas cada día durante el primer trimestre del 2019 y únicamente un $25 \%$ de los casos son investigados como feminicidios. En suma, del 2012 al 2017 han sido 7,404 mujeres asesinadas, según el Observatorio Ciudadano Nacional del Feminicidio. 
(15). Por esta razón, la igualdad entre el hombre y la mujer ha sido un concepto que se convirtió en el instrumento principal de las conquistas legales de las mujeres de Occidente; tanto fue así que se transformaron en personajes que representaban a la clase media que pobló la literatura de consumo en la modernidad.

Otro aspecto, en España, en el año 1979 se presentó Picadura Mortal, la primera novela negra con una protagonista femenina, ya que en ella, "la mujer toma por primera vez el lugar del hombre. Mediante esta presencia, la mujer tiene una participación igual a la del detective masculino, y al mismo tiempo, a través de la parodia, se rompen los estereotipos femeninos de la novela negra tradicional" (Choi 13). De este modo el movimiento feminista en los países desarrollados, en particular de la clase media, planteó cuestiones que oprimían a las mujeres generando inquietudes y cambios drásticos en su conducta social e individual.

Mediante la coherencia, Eric Hobsbawm en la Historia del siglo $X X$ (1998) amplía, "las mujeres fueron un elemento crucial de esta revolución cultural, ya que esta encontró su eje central, así como su expresión, en los cambios experimentados por la familia y el hogar tradicionales, de los que las mujeres siempre habían sido el componente central" (Hobsbawm 321). Para caracterizar a las voces femeninas, como un distintivo que cobra auge en la novela negra, Bolaño establece parangones naturales porque la naturaleza de la posmodernidad está para él investida de los más admirados atributos actuales. A su vez, posee el mismo dinamismo y sufre de todas las mutaciones del mundo natural, de ahí el título de las detectives femeninas, es decir, las Putas asesinas.

Si desde la modernidad la mujer ha sido la protagonista de los feminicidios, en la posmodernidad no podemos dejar de advertir, como médula espinal, una asociación que comienza desde con Esferas I, una alianza sonosférica (Sloterdijk 230), es decir, estampaciones musicales y extrañas en el mundo, donde ahora los iconos femeninos son las imágenes de ellas, las que en el momento liquidan, persiguen el mismo orden y validez de los sujetos occidentales. Con este libro de trece cuentos bolañianos, se clausura la esfera de la madre - concepto 
que Sloterdijk perfila en su obra-, la transmisión de los pensamientos de la sumisión, todo se abre hacia un drama de la vida en el cual se abandonan los espacios animados, sulfura un recambio habitable, que comienza con la primera fatalidad de las esferas: el nacimiento que es la sentencia, y el seno de la dolencia en Esferas I (Sloterdijk 5).

La historia en la ciudad del siglo $\mathrm{XX}$ es el resorte temático bolañiano, en donde también se inmiscuye la mujer como una esfera dentro de otro punto de intersección narrativa que irá conformando la ciudad literaria. Si ya desde Los detectives salvajes y Amuleto, la esfera de la mujer se repiensa como esa nueva apertura de la madre, la voluptuosidad de la periferia abre el juego del límite, la mujer desde nuevos presupuestos teológicos que gritan un vaciamiento de lo propio, de lo obligado: Cesárea Tinajero y Auxilio Lacouture. Y bajo esta conformación de nuevas entrañas, las féminas de Putas asesinas y 2666 no son presentadas por casualidad, pues son más bien personajes que subvierten los roles asignados al género femenino de la primera década del siglo XXI. Actúan como dispositivo de la sublevación cultural, en el que la mujer perturba los comportamientos impuestos por el imaginario machista en el ámbito de la sexualidad y, por medio de la palabra, manifiestan su erotismo defendiendo su autonomía. Aquí se piensa en la mujer como una geómetra del vanguardismo, de la urbe, del entretiempo. Comencemos por lo que Sloterdijk define como agrimensor, en suma, el hipotexto se define en Esferas I: Burbujas. Microsferología:

¿Qué es un ser humano en la era académica sino un mamífero desmemoriado que por regla general ya no sabe que en el fondo de su alma es un geómetra? Un geómetra, ¿qué es eso? Una inteligencia que viene del mundo de los muertos y trae a la vida vagos recuerdos de su estancia en una esfera perfecta. La filosofía comienza a ser efectiva exotéricamente cuando divide la sociedad entre aquellos que recuerdan y aquellos que no recuerdan; y, además, entre aquellos que se acuerdan de algo determinado y aquellos que se acuerdan de algo diferente. Éste viene siendo hasta la fecha su negocio, aunque los criterios para la división se hayan complicado un poco (8). 
Los iconos femeninos son los que ponen de manifiesto la problemática del espacio interior, son la anatomía moderna que profundiza en el campo de la mecánica de los movimientos internos de fluidos: de la ciudad globalizada. Ciertamente, Bolaño expone la tesis fundamental, vivir es cuestión de forma: esfera. Así pues, en la transición de la ciudad industrial, las esferas bolañianas comienzan a experimentar a partir de la urbe, la condición posmoderna. Pues la sociedad empezó a concebirse como una red de comunicaciones, en donde el vínculo con lo social se componía con la reciprocidad agonal (Anderson 37). Intrínsecamente, en los relatos se plasma la esferología mundana, a la par de las prácticas discriminatorias respecto a la mujer en sus relatos, el símbolo envolvente de la fémina o del ser-alrededor, puesto que abarca un género entre lo físico y espiritual, dicho de otra forma, se entreteje como ese sitio que se inclina sobre la bola todopoderosa (Sloterdijk, Esferas III... 535). Dentro de este abovedamiento se suman los feminicidios de 2666, que se superponen a la modernidad de la ciudad. Ofrecen a su vez descripciones extensas porque la urbe desencadena una problemática compleja; implica zanjar una cuestión crucial que concierne a todas las narraciones. Esta es la relación entre espacio y urbe, la dimensión se organiza sobre en cuánto recuerda la esfera. Imaginar a la mujer entre violaciones, asesinatos, y mujeres que se ganan la vida por medio de las intensas jornadas laborales en las maquiladoras de Santa Teresa, constelación interfacial de cuerpos y manchas de sangre en 2666: "La vagina estaba desgarrada. La vulva y las ingles presentaban señales claras de mordidas y desgarraduras, como si un perro callejero se la hubiera intentado comer" (Bolaño 281). En contraposición, se encuentra en Putas asesinas cómo se cumple el gran cambio modélico de la esfera de la mujer, de la protoescena, a modo de esquema de la imagen, es decir, paradigmas que contienen como trasfondo nuevos patrones visuales.

Rostros femeninos que referencian la acción y la escena, la vida represiva comienza a abrirse hacia el espacio moderno de la nueva operación, aunque este libro de cuentos se haya escrito tres años antes de 2666, posibilita la grieta del espacio-entre-rostros, narraciones faciales de la lucha icónica. En el relato de "Fotos", no es casualidad 
que el protagonista, un Belano ya adulto, profundice sobre Nadia Tuéni, cuando encuentra alguna de sus fotos, y más aún, que la fecha infiere a la década de 1970, los años del 73 o 74, en donde otra vez, nos arguye las relaciones con otros, que, con rostros (o fotos) cambiantes, siempre enfocan hacia el mismo lugar. En el texto, Esferas I, es posible advertir que el rostro femenino es la irradiación corporal del regazo materno, lo primario: "La protoescena de la musa se elude en los sujetos mal desligados o paridos de la Modernidad; la libertad para quejarse por el otro perdido desaparece en la insensibilidad e informidad" (Sloterdijk 188). De esta forma, si bien se da un nuevo giro para pensar a la mujer, es la imagen de la esfera dominante, a saber, hay de putas a putas. Roberto Bolaño marca una nueva ontología en la escena fotográfica,

Y entonces Belano casi pega la cara a la página para ver con más detalle a las poetas, y Nadia y Venus le parecen francamente hermosas, con Nadia follaría, se dice, hasta el amanecer (suponiendo que en algún momento caiga la noche, pues la tarde en la aldea parece seguir al sol en su marcha hacia el oeste, eso piensa Belano no sin acongojarse) y con Venus follaría hasta las tres de la mañana, y luego me levantaría, encendería un cigarrillo y saldría a caminar por el Paseo Marítimo de Malgrat, pero con Nadia hasta el amanecer, y las cosas que le hiciera a Venus se las haría a Nadia, pero las cosas que le hiciera a Nadia no se las haría a nadie más, piensa Belano mientras observa sin parpadear, la nariz casi pegada al libro, la sonrisa de Nadia, los ojos vivaces de Nadia, la cabellera de Nadia, oscura, brillante, abundante, una sombra protectora y eficaz (Bolaño, Putas... 202).

Sin duda, para la georreferenciación geométrica, el contexto se elabora, remite y significa mucho en la década destacada en el cuento. Es una metaficción, autorreflexiva, autorrepresentativa, y narcisista, concepto acuñado en 1970 por William H. Gass con su obra, Fiction and the Figures of Life. De modo que, es una forma de literatura que no solo está atenta a su status como artefacto sino que también se inquiere sobre la relación entre ficción y realidad. E inclusive explora la posible ficcionalidad del mundo que existe fuera de la ficción literaria y del texto (Waugh 4). Para ahondar en dicho mundo, los íconos femeninos bolañianos: Cesárea Tinajero de Los detectives Salvajes, Auxilio 
Lacouture de Amuleto, y todas las putas asesinas, convierten en ficción los efectos culturales del siglo XX, periodo caracterizado por las guerras. En la narrativa de Bolaño se profundiza en la contienda que se vive desde la perspectiva de las mujeres, en especial, la revolución sexual occidental de los años sesenta y setenta, la cual se dio gracias al descubrimiento de los antibióticos después de la segunda guerra mundial, y también con la invención de la píldora anticonceptiva, aunque el peligro regresaría al sexo en la década de los ochentas con el SIDA (Hobsbawm 301). En definitiva, el discurso de lucha y empoderamiento femenino llega a su máximo nombre y rostro con Putas asesinas. Las mujeres convertidas en una fuerza esférica y destacada como nunca antes lo habían sido en la historia, el doble juego textual entre la asesina y la puta que te hace descender a su propio infierno.

Bajo este escenario de lo redondo, se sigue pensando en el espacio femenino. Las protagonistas de Putas asesinas extrapolan la búsqueda de la expansión del urbanismo. En gran parte de Hispanoamérica se aprecia que las primeras representaciones literarias de la ciudad aparecieron a través de los viajeros quienes contribuyeron con sus impresiones visuales y crónicas. Las femmes trotamundos detallan y conceptualizan la vida urbana con rapidez y desenvoltura, aunque en algunas ocasiones dictan con prejuicio o generosa fantasía lo que vieron o lo que quisieron ver. La mujer mira como el viajero, marca estructuras espaciales con signos distintivos para la ciudad, "Ahora no hay tiempo para aburrirse, la felicidad desapareció en algún lugar de la tierra y sólo queda el asombro. Un asombro constante, hecho de cadáveres y de personas comunes y corrientes" (Bolaño, Putas... 112). Con base en esto, Bolaño plantea pensar a la mujer a partir de ese espacio que se aleja del poshumanismo: aro catalizador que opera desde el pasado hasta el presente.

Además, es un signo de esperanza convencional, la mujer ya no ha de estar ahí sólo para los hombres, su voz revienta el mito adánico; ella significa libertad, seducción, nuevos ciclos de vida. Y la radicalización de la voluntad propia. Lo humano recobra solidaridades desde el comienzo, vuelve a estar inmerso en las esferas femeninas, pero a su 
vez, hace una vuelta de tuerca, en Putas asesinas (2001), son las que ahora asesinan bajo una inclinación significada:

Han intentado matarme, una jodida puta del extrarradio de la ciudad, de las afueras de la ciudad y del tiempo, una puta del más allá que me vio en la tele (¡salimos en la tele!) y que me llevó en su moto y que me la chupó y que me ofreció su culo y que me dijo palabras que al principio me sonaron misteriosas pero que luego entendí, o mejor dicho sentí, una puta que me dijo palabras que sentí con el hígado y con los huevos y que al principio me parecieron inocentes (Bolaño, Putas... 124).

Lo anterior inspira. Existe una primera esfera que vive pensando en su espacio, en su intimidad, trata de entender esa ontología de saber que ahí, en la circunferencia se encuentra la verdadera ontología del espacio: Auxilio Lacouture de Amuleto. Auxilio es la mujer madre con un rostro diferente se sale del retrato, no es suficiente buena, ni bella, pero conecta con el resto de los personajes como semejantes suyos o con un Otro al autonombrarse como la madre de la poesía mexicana (Bolaño 11). La belleza de la mujer se despoja del vacío adjetival. En el caso de Auxilio se introduce el cambio de la condición femenina, deja de ser la madre y ama de casa, exenta de moral severa, abandona el rol de mujer resignada, e inclusive existe ese duelo esférico con la conmoción social de nuestra época, en el cual se marca el futuro a partir de la emancipación femenina. Para Gilles Lipovetsky es posible describir esta condición, puesto que en se ha instaurado una nueva figura social de lo femenino en las sociedades occidentales, una ruptura capital en la historia de las mujeres que indica una evolución democrática aplicada al estatus social y de identidad femenina. Ahora surge una figura sociohistórica que señala en su libro La tercera mujer (10). Esto implica que deja de estar preordenada, es la nueva madre sin arcaísmos, y de autonomía subjetiva. Además, Auxilio retoma el año de 1970 en sus narraciones para detallar que fue el principio en que se reestrenó su papel de madre, pero de los poetas mexicanos: de los realvisceralistas.

Pensar sobre la esfera de la mujer como el corazón de la modernidad, es el camino de los relatos, y la trasmisión de los pensamientos 
bolañianos. Si en el juego semántico de violencia-violación, la mujer llama su libertad, en otro de los cuentos indispensables de Putas asesinas, "Prefiguración de Lalo Cura", se repasa a la mujer a partir de la vinculación de un estereotipo de victimización: dominada, sometida o violada. Por lo tanto, Bolaño coloca a la pornografía como una revelación que conecta con el centro, pero que denuncia la "inferiorización de lo femenino"; de hecho, Lipovetsky define dicho concepto, "No tanto una moral de los placeres como una política del varón destinada a consagrar la dominación masculina mediante el artificio de prorrogar la imagen de la mujer puta, la mujer servil y vulnerable, la fémina estúpida, engañada, mero objeto de goce" (La tercera mujer 36). De esta manera, debemos mencionar que la posmodernidad inaugura una nueva expresión en la pornografía, puesto que consigue su mayor presencia a partir de los años 70' hasta la actualidad. De nuevo, es la década como círculo, o pelota lanzada en donde se mueven las esferas féminas. En el relato que mencionamos se alude la Productora Cinematográfica Olimpo dedicada a las películas pornográficas, semiilegal, que cobró auge y se desplomó hasta mediados de los ochenta. Además, se rescata la voz-clausura del espacio de Connie Sánchez, la progenitora de Olegario, porque para prefigurarlo hay que entenderlo desde el primer espacio: abierto, dañado, usado, y colmado de orgasmos personalizados. Las asimetrías que imposibilitan la imagen y semejanza de la madre como experiencia ontológica de la ausencia,

Ahí está Connie: gorda, rubia, y yo dentro, hecho un ovillo, mientras ella ríe y unta con vaselina el culo del Pajarito Gómez. Sus movimientos ya son los movimientos delicados y seguros de una madre. Abandonada por el imbécil de mi padre, ahí está Connie, con Doris y Mónica Farr, sonriéndose intermitentemente, intercambiando muecas y gestos imperceptibles o secretos mientras el Pajarito mira como hipnotizado la barriga de Connie. El misterio de la vida en Latinoamérica. Como un pajarito delante de una serpiente. La Fuerza está conmigo, me dije, la primera vez que vi la película, a los diecinueve años, llorando a moco tendido, haciendo rechinar los dientes, pellizcándome las sienes, la Fuerza está conmigo. Todos los sueños son reales. Hubiera querido creer que las vergas que penetraron a mi madre se encontraron al final 
del sendero con mis ojos. Soñé con ello a menudo: mis ojos cerrados y translúcidos en la sopa negra de la vida (Bolaño, Putas ... 100).

Desde el principio, el espacio de la mujer se piensa desde lo humano, en el ab útero, madre-hijo es lo más cercano, porque el "serjuntos" en los seres humanos se produce el interior. El comportamiento entre Doris-Olegario es el ardid de unión dúplice: siempre buscando el hueco. Un puente de regreso con el primer espacio de existencia. Pero en el relato se habla también de otra mujer, Doris, la mejor amiga de Connie. Ambas putas, ambas como la representación del film sobre las convulsiones del espíritu, ambas figuras de liberación sexual, ambas como círculos del hedonismo y ambas como campo del horror y del espectáculo del mundo. Ahora, ¿Por qué se puntualiza la pornografía en el relato para desdoblar la esfera del yo a partir del vínculo con la madre? La esferología femenina es la liberación del estigma de la sumisión desde el alumbramiento materno. La Sexducción, la cual señala Lipovetsky en La era del vacío, como respuesta ante la inflación erótica actual y de la pornografía que denuncia y reconcilia a las feministas y los escandalizados por rebajar la condición humana a lo cosificable, máquina sexual, porque las relaciones de seducción se circunscriben en una orgía sin misterio; es decir, destruyen el orden laico, la ley, la censura. Con todo, la pornografía se convierte en la espumidificación de otros globos ${ }^{4}$ que habitan en esa capa de líquido globular. Modulables y proferibles, los globos son cuerpos esféricos que se rellenan a partir de lo exterior. Georreferenciación bolañiana: el nuevo orden industrial, la disposición de los cuerpos seriales, los vertederos humanos, el espacio como empresa que se convierte, "Contrariamente a lo que dicen sus detractores, en un agente de desestandarización y de subjetivización del sexo y por el sexo, al igual que todos los movimientos de liberación sexual" (Lipovetsky, La era... 23). De tal forma, el campo amniótico es el puente con el vacío que se da desde la microesfera, y con el cuerpo de la madre como orgía tempoespacial.

\footnotetext{
${ }^{4}$ Sloterdijk ha señalado en Esferas III. Espumas. Esferología plural (2006), para una diferenciación mejor, a las esferas como el aspecto íntimo de la conformación del ser humano "dentro y entre" el ser humano, pero existen "las grandes esferas desde los imaginarios globos celeste y terráqueo hasta las reales circunvalaciones terrestres y conquistas del mundo, y hasta lo que hoy llamamos globalización" (9).
} 
Las esferas de la mujer son las verdaderas putas asesinas, sobrecarga antropológica para la capacidad de aprender. Otorgan un sentido del humor puesto que al erotismo femenino se le resbala el sexo duro: "sino de la obsesión moderna con lo real, del deseo de rebasar todos los limites (...). Frente a la proliferación del porno duro, que mecaniza el sexo, la respuesta adecuada de un feminismo adulto debería ser, precisamente, la risa o la burla" (Lipovetsky, La tercera mujer 81). Estar inmerso en el mundo es "estar más cerca de mí que yo mismo", caer en la trampa de la pornografía "es habitar en". En el cuento "Prefiguración de Lalo Cura", el protagonista al ser hijo de una actriz porno, inaugura la esferología del matriarcado, y la topología femenina a partir de la expansión, pero también existe un flujo en esta geometría: la mujer violada que persigue la curvatura de la catástrofe latinoamericana: la pornografía como globo de la violencia, es decir, no deja de ser un cuerpo esférico, pero relleno de aire. De esta forma, la conformación de la forma, la imagen de la mujer deja de ser el blando órgano femenino. Así pues, Bolaño eleva en el aire el discurso de la modernidad, globografía del mal humano. El protagonista, Lalo Cura, relata el desencantamiento de su mundo:

En aquella época, cuando aún era joven, me costaba emplear la palabra matar. Nunca mataba: daba el billete, borraba, hundía, desintegraba, hacía puré, desmenuzaba, dormía, pacificaba, quebrantaba, malograba, abrigaba, ponía bufandas y sonrisas perennes, archivaba, vomitaba. Quemaba. Pero al Pajarito no lo quemé, sólo quería verlo y platicar un rato con él. Sentir su tictac y recordar mi pasado (Bolaño, Putas... 111).

Algo similar ocurre con el cuento que le precede, Putas asesinas, red de las líneas geométricas en todos los relatos, analiza los indicios que, poco a poco, van apareciendo de nuevas alineaciones de esferas en 2666, en donde es posible advertir un "topoanálisis" de espacio, y elementos psicológicos para realizar la trayectoria de esfera a burbuja. Meditar sobre la mujer a partir de su espacio interior y como máxima estructura esférica de vida es encontrar las interconexiones horizontales para la movilidad del discurso. Son cosmógrafas que disfrutan el espacio interior y el espacio vivido, esferas en complicidad, ponerse ellas mismas en conexión que envuelve la vida de cualquier otra. Pensar en estas esferas implican de forma inevitable, enajenarse en la 
inmensidad, como un cargo de estancia investigadora hacia el exterior; a saber, ya no del espacio feliz, sino de los espacios de hostilidad evocados en las páginas de 2666. Esos espacios del odio y del horror que son referidos por medio de las imágenes femeninas, en donde existe una estética de lo oculto, y para captar esa fenomenología de lo oculto, existe una observación preliminar: solo puede ser pensado (Bachelard 23). Lugares inimaginables convertidos en espacios vividos: el vacío de los seres humanos.

\section{Burbujas fuera de sí, ciudad de la frontera, sistemas de vertederos. Hacia una ontología del espacio}

La ciudad tuvo un nuevo giro surgente en la posmodernidad: punto de máxima tensión de todo sistema social debido a la división del trabajo. En dicha evolución, para los países de América Latina, la introducción del cambio produjo un cambio globalizado que alteró la configuración urbana. En el desarrollo de la vida se olvidó de lo rural, se volvió difícil definir lo que se entendía por ciudad, dicho de otra manera, dado que no se entendía el historicismo de la urbe: industriales y administrativas, políticas y servicios, ciudades portuarias y turísticas, aunque la mayor complejidad quedó patente en las megalópolis que no pudieron simplificarse bajo características monofuncionales (Signorelli 33). Posteriormente, desde el siglo XVIII hasta la segunda mitad del siglo XX, el estado-nación sufrió un debilitamiento en dos sentidos; primero, en la pérdida de poder y atributos como entidad supranacional al producir pequeños estados que nunca fueron lo suficientemente fuertes para protegerse de las anarquías internacionales; y segundo; al debilitarse su monopolio de fuerza y privilegio histórico en el marco de sus fronteras. Todo lo anterior fuertemente ocurrió entre 1970 y 1989 (Hobsbawm 468), obteniendo como resultado espacios sociales tan complejos como la ciudad del siglo XX.

El sinsentido del ser humano lo ha condenado al exilio, a moverse, a ahuyentarse de sí mismo, perdiendo así la confianza, y el cobijo con otros humanos, burbujas que le ayudan a moverse, pero que hoy se ha convertido en algo inconsciente tanto físico como superfluo. Urbanitas que ya desde finales del siglo XIX — con los europeos-, conocieron 
el poder de ser capaces de construir y contemplar desde el espectáculo del culto, a las imágenes y globos terráqueos, ya que por medio de la contemplación de ambos mantuvieron la certeza de la existencia sobre un globo, nunca más dentro de uno. A pesar de todo, lo que hoy se conoce como globalización deriva de tal juego; es decir, con ese globo excéntrico advertido desde con Esferas $I$ en la Introducción general (Sloterdijk 3). Es entonces cuando la ciudad comienza a exhalar, el espacio transporta las pompas del mal y del horror hacia afuera, a partir de la imagen del personaje que narra, todo se dilata y la burbuja estalla. Bajo este escenario, Bolaño advierte la crisis general del espacio en su novela 2666 a partir de las trasferencias de las esferas en la horrible ciudad de Santa Teresa,

Este país es increíble (aquí hacía una digresión, pero sólo en la carta a Espinoza, como si Pelletier no pudiera entenderlo o como si supiera de antemano que ambos iban a cotejar sus respectivas cartas), uno de los mandamases de la cultura, alguien a quien se supone refinado, un escritor que ha llegado a las más altas esferas del gobierno, es apodado, con toda naturalidad, además, el Cerdo, decía, y relacionaba esto, el apodo o la crueldad del apodo o la resignación del apodo, con los hechos delictivos que estaban ocurriendo desde hacía tiempo en Santa Teresa (Bolaño 90).

Bolaño representa el espacio humanista que se degrada en su dispositivo urbano, es decir, refleja la ciudad industrial que despoja a las esferas humanas ya sea como espacio animado o como globo concreto o abstracto del ser; provocando el lugar fracturado, el que recae otra vez en el vacío pues lo anunciado se "espumidifica" en la nada. Las mujeres bolañianas - aunque simulan un interior sin cobijo- incorporan los últimos valores modernos, realzan el pasado y la tradición los legitima mediante la afirmación de la identidad personal sujeta a los valores de una sociedad que ha empezado a exhalar, ya los mismos personajes notifican, "En el siglo XIX, a mediados o a finales del siglo XIX, dijo el tipo canoso, la sociedad acostumbraba a colar la muerte por el filtro de las palabras" (Id. 162). Podríamos decir que, 2666 es una novela ontológica del espacio, en comparación, en ninguna se reflexiona más sobre lo contemporáneo. Además, realiza conjeturas y extraversiones 
desde lo inmenso hasta lo inquietante: una conceptualización del espacio apropiado del siglo XX. Es en este tiempo en que las formas de aniquilación cobraron dimensiones morfológicas en que la urbe adquiere la dimensión de un desierto, del "oasis de horror", para finalmente ocupar el silencio en la existencia cotidiana.

También, el éxodo humano designa la apoteosis de lo temporal en este relato, las mujeres errantes se encuentran en tensión, son las burbujas fuera de sí, en donde es el espacio quien provoca la ilusión entretejida que desemboca en la ciudad. Siempre juntos, personaje y espacio persiguen la geometría de lo redondo, es decir, exhalador y burbuja habitan en un campo desplegado por el individualismo. Ambos provocan artificios escénicos, porque no podemos olvidar que el espacio en la narración siempre nos plantea espacios irreales con el nombre de "basureros" en donde son arrojados los cuerpos en Santa Teresa, vertederos en los que sus referentes son explícitos y reconocidos.

Para entender la geometría esferoidal, debemos seguir la lectura esclarecedora del espacio como muerte. Si en Amuleto el espacio de la muerte se reduce a un pequeño baño de la UNAM, la voz poética de la protagonista subyace a la inercia con la que el horizonte de esperanzas se ha ido apartando de los espacios de experiencias del pasado y solo queda el presente que apunta hacia el fin. Caso contrario ocurre con 2666, en "La parte de Amalfitano" se advierte que la muerte se ensancha, y proyecta nuevas gesticulaciones poliesféricas. Santa Teresa es la ciudad-espuma en donde la mujer es una burbuja aislada puesto que no se introduce en el hiperglobo de la violencia, es decir, sino que es en ella en donde se concentran las irregularidades. Las féminas amueblan mediáticamente los espacios de la muerte en donde Bolaño expone la enorme curvatura de la expiración como lugar. En esta novela la reconstrucción del mundo es paralela a la geometría diestiana - continuando con la idea iniciada desde Bachelard, que formulaba que para comprender el mundo hay que detenernos en el espacio-, es pensar en el progreso como la transparencia del mal a partir de la geometría de ser en el mundo en la "era-redonda". Bolaño registra, como síntesis esta historia: 
En la solapa se advertía que aquel Testamento geométrico eran en realidad tres libros, "con su propia unidad, pero funcionalmente correlacionados por el destino del conjunto", y después decía "esta obra de Dieste, decantación final de sus reflexiones e investigaciones acerca del espacio, cuya noción se halla implicada en cualquier ordenada discusión sobre los fundamentos de la Geometría" (115).

La mujer en la ciudad enclaustra la añoranza, el pasado, la juventud, el ímpetu, las calles-báculo de violencia, el movimiento, el encierro y la muerte, todo en intimidad con el mundo. Si limitamos en esta etapa nuestras reflexiones a la afirmación bolañiana acerca de la muerte como resultado de una operación de condensación realizada por el vacío en el espacio narrativo hipertextual, podríamos señalar esta idea como un sintagma referencial: la intimidad del yo, pero cuando no se les permite estar aisladas, es cuando rompen con la idea de la espuma global, dicho de otro modo, estar fuera de sí es estar desprotegido: la mujer es asesinada, el hombre contempla bajo la exaltación del rompimiento. Es en esta armónica desintegración de universos y en esta continuidad hacia un proceso de consolidación del vacío, el hipertexto de 2666 se resigna a consignar la muerte donde la imagen de la urbe y el espacio evocan un relato bajo el mismo horizonte. Ahí la operación narrativa de Bolaño es, "cara a cara con la muerte" pues las diversas historias que se narran en la novela concurren, en un momento u otro, en la ciudad mexicana de Santa Teresa, la cual funciona como una reproducción de Ciudad Juárez. Hablamos de un lugar de autoría del mal donde se funde el noúmeno, nos referimos al término problemático que señala Sayak Valencia en su obra Capitalismo Gore (2010), en particular, la experiencia personal con la ciudad fronteriza, como lo otro; es decir, ese lado "B" de la globalización, el lado oscuro del capitalismo y del neoliberalismo — este último presenta un desmoronamiento en pleno 2019 con varios países de América Latina-, volvemos al carácter contradictorio de la ciudad marginal o al borde. La autora la define como Ciudad del over and over again, (aunque se refiere específicamente a Tijuana), lo borderline es una de las estructuras privilegiadas dentro de los relatos posmodernos y precarios, aunque sea el sentimiento trágico y analógico de la existencia: ciudad 
+ mujer; esto es, al borde de una esfera arbitraria, pero que pretende resistir a esa pequeña sujeción porque no todo está a la luz,

Una mujer-border se parece a la muerte y deambula con una mano unida a un revólver. El Hombre-Jeringa emprende un vuelo fallido en medio de la serpiente metálica. Los transparentes y los ciertos. Los punzantes. El primer y el tercer mundo. La frontera. El infierno. La otra parte del otro lado. El otro lado del otro lado. El Este lado del Otro lado. El mundo feliz del desengaño (Valencia 14).

2666 es el proceso de personalización en donde se presenta una connotación de inferioridad, de deformidad, de pasividad, de agresividad para consecutivamente reventarse en el lenguaje neutro de las sociedades individualistas (Lipovetsky, La era ... 17). La ciudad tiene un rostro, nos hace volver la vista hacia los vertederos de posmodernidad, y por ende, del capitalismo gore, entendiéndose como el término reinterpretativo sobre la economía hegemónica y global en los lugares fronterizos, en donde nos apropiamos de dicha expresión:

Gore de un género cinematográfico que hace referencia a la violencia extrema y tajante. Entonces, con capitalismo gore nos referimos al derramamiento de sangre explícito e injustificado (como precio a pagar por el Tercer Mundo que se aferra a seguir las lógicas del capitalismo, cada vez más exigentes), al altísimo porcentaje de vísceras y desmembramientos, frecuentemente mezclados con el crimen organizado, el género y los usos predatorios de los cuerpos, todo esto por medio de la violencia más explícita como herramienta de necroempoderamiento (Valencia 15).

La realidad de la urbe posmoderna incluye una interrelación, que podría considerarse intrínseca con el campo del vacío, entendiéndose el "vacío" desde la concepción filosófica donde es la ausencia del ser en la esfera: el símbolo desaparece, dando como resultado un signo como significante pero sin significado. Aquí se produce la muerte de las mujeres en Santa Teresa, así como toda otra serie de atrocidades que se dan en ella. La ciudad genera un espacio de opresión y un espacio vacío en contraste con el universo del todo. El personaje de la periodista, Guadalupe Roncal en "La parte de Fate" de 2666, advierte cuando las esferas están fuera de sí, pero: "Nadie presta atención a estos asesinatos, 
pero en ellos se esconde el secreto del mundo" (Bolaño 217). La espumidificación del vacío genera el sitio de la muerte que poco a poco carcome a la ciudad, y es que "Nos hemos acostumbrado a la muerte", frase que actúa como la elegía en la narrativa de 2666. Asimismo, esta dependencia que establece Bolaño entre una urbe del norte de México - Santa Teresa - y la muerte que encarna como macrofigura en el espacio proyectado en esta novela es, entonces, una red englobante: amor, madre, sociedad, mujer, asesinatos. 2666 significa, entonces, el espacio humano, la presencia de un entorno y de un paisaje mexicano que expresa dolor/muerte. Bolaño nos indica que la ciudad de Santa Teresa posee una cartografía de desesperanza; es decir, los asesinatos tipo rituales de niñas y mujeres hacen posible conocer las cifras de la destrucción del mundo actual. 2666 es el globo que tiene los dígitos de la muerte en los cuales el autor chileno nos expresa: se está fundando el futuro del mundo. México, espacio de la muerte, en donde se proyecta el porvenir de los urbanitas. Aquí Bolaño nos pone de frente a la inmunidad-nosotros a través de cinco historias subrayando el absurdo de las interacciones urbanas y sociales; estas últimas aparecen enmarcadas dentro de la crítica sobre la condición industrial más una reflexión urbana sobre la metrópoli. Además, la intersección de modos culturales coloca el espacio no solo como lo vivido y habitado a partir de una vida que actúa ilimitadamente, "sino más bien porque todas están ensambladas con otras vidas y se componen de innumerables unidades. La vida se articula en escenarios simultáneos, imbricados unos en otros, se produce y consume en talleres interconectados. Pero lo decisivo para nosotros: ella produce siempre el espacio en el que es y que es en ella" (Sloterdijk, Esferas III... 12).

Bolaño utiliza estos lugares para orientar la historia de la ciudad y para subrayar las divisiones de clase social que trazan los personajes, en particular las entidades femeninas en las urbes, apariciones a manera de latiguillo, "todas las ciudades son parecidas" (Bolaño, 2666 105). Para el escritor chileno su preocupación es pensar el espacio, pero más el que ocupan las mujeres, puesto que son las que dirigen el discurso de los relatos: el sitio de existencia del hombre contemporáneo. En Los detectives salvajes y Amuleto, se realiza la "sumersión abismal en lo 
más cercano", a partir del espacio esférico del humano: la madre. Es por eso que en ambos relatos se dan en espacios que buscan la existencia de la progenitora; primero, Cesárea Tinajero, la madre de todos los real visceralistas, pero también concurren 150 referencias sobre las madres de los otros detectives. A este punto, no son solo los personajes quienes buscan estar cerca de ella, sino porque ella es la conexión espiritual con todos los Infras perdidos y eso es lo que los mantiene inmersos en la burbuja de los ocupantes-ocupados, extraviados entre la ciudad y el desierto, en la búsqueda eterna de Cesárea.

Por su parte, Auxilio Lacouture es también la representación de la intimidad primaria, la esfera íntima que conlleva a la existencia de un segundo, es decir, habitar en esferas demanda ser gemelo, empezar a contar desde dos, que es lo que nos lleva a habitar en burbujas (Sloterdijk, Esferas I... 185). La relación "íntima" de Auxilio con los poetas y su territorio amparándose en la mitología y el éxodo, esto es, estrategias ontológicas que muestren el pensamiento histórico que vincule el proceso urbano y toda la microesferología que no logra encajar en todas las máquinas de animación: migración, multiculturalidad, nomadismo y diáspora de vida. En efecto, los personajes solo pueden desarrollarse como sí mismos cuando es posible una referencia de fondo, con una vida paralela, ligada y que fluya en él, del símbolo de la gran madre nutricia que encierra en ella el principio de la libertad. Ellos niegan el espacio interior y crecen frente a las provocaciones del "afuera", desde otros espacios de la muerte,

El montaje en un espacio determinado de objetos inanimados extraídos de la vida cotidiana, cuyo rol es gatillar por antonomasia el potencial aesthésico de la representación (dar "vida" a la representación), provocando en este acto un efecto de armonía, serenidad y bienestar, pasa a convertirse, tras el desplazamiento semántico al que es sometida luego de asociarse al espacio geopolítico de Santa Teresa. Así, la "naturaleza muerta", extrapolada a la cartografía de Santa Teresa, "representa" el lugar donde lo que "muere" es una forma de aesthesis concebida bajo los fundamentos de la estética moderna. Esta muerte o anulación se implanta bajo la forma de una terminal im-potencia frente al umbral de percepción del escenario descrito en el desierto mexicano (Soazo 231). 
En términos fenomenológicos, acompañar a los protagonistas a partir de la existencia de la mujer por el espacio, para mantenerla viva, no obstante, "afuera" es pensarla hacia la muerte. Con esta metáfora, Bolaño ofrece una hipótesis de la época actual: la vida en el lugar es un desarrollo espumoso. El espacio, todo el espacio es la ciudad. Su punto de partida consiste en una definición con lo urbano, lo violento y lo transfigura en una esfera animada que es la zona que hay entre mujer y objeto, contemplación del vacío que existe desde el interior del hombre. Asimismo, la evolución de este espacio resulta notorio gracias al peso de los personajes femeninos; si bien vemos que desde Putas asesinas se adquirió un matiz en el cual, "Una vez que el componente vampírico adopta la identidad femenina, en ella se encarnarán los miedos y temores de una cultura que percibe a la mujer como un ser empeñado en dominar, succionar y devorar al hombre. Así convertida en mito y leyenda o emblema y parodia de la perversidad" (Del Pino y Rodríguez 145). En 2666, la última novela que analizamos, se enfatiza la idea de la victimización de la mujer, fuera de sí, como una de las características de la literatura contemporánea; no obstante se asoma en el espacio de la muerte el papel de la mujer emancipada: Liz Norton, de la "La parte de los críticos", Lola en la "La parte de Amalfitano", y, posteriormente, Elvira Campos en "La parte de los crímenes". El espacio de la muerte ordenará la nueva manera de entender el lugar que ocupa la mujer en la ciudad industrial.

Sobre este mismo horizonte, surgen con esto varias perspectivas esféricas encarnadas por los personajes femeninos, quienes en esta situación muestran una mayor conciencia y un pensamiento poshumanista de las divisiones internas del yo: una microesfera que posea un espacio con la capacidad de aprender. A través de las mujeres se ofrece el sentido del "dónde", puesto que con ello se dirigen al espacio para poder existir como ellas son y desean ser; es un doble signo porque con ese "dónde" también se coloquen esféricamente en un no-ser: cosificable, abusada, víctima de la infamia, engañada, agraviada y asesinada como blanco encarnizado de la posmodernidad. 


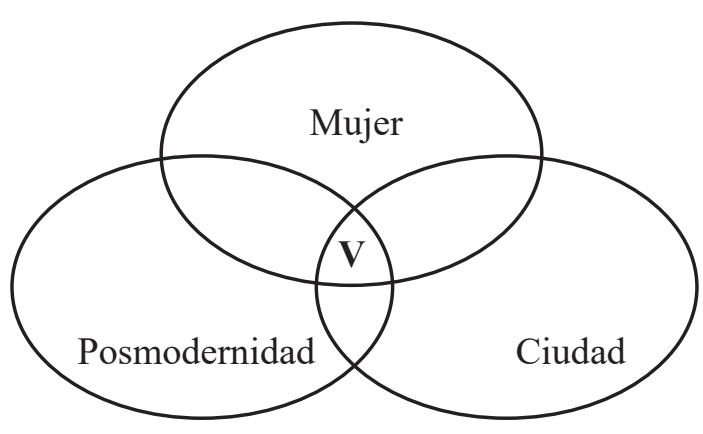

Figura 1. Idea geométrica del espacio vacío en Bolaño

\section{Conclusiones: Donde comienza a equivocarse la humanidad, geo- metría del vacío}

En las cuatro obras aquí analizadas, Bolaño alude a la estructura elemental de la violencia que los hombres ejercen sobre las mujeres para delimitar el espacio que encubrirá y propiciará estos crímenes de odio contra ellas. Con el arribo de la Ciudad industrial, las mujeres jóvenes de Santa Teresa en 2666 (Ciudad Juárez) se convirtieron en las poseedoras del empleo y del dinero, al contrario de la estructura patriarcal que hasta antes dominaba. En definitiva, en la novela también se habla de ser-ellas en el espacio vacío, "Las mujeres brillaban por su ausencia: o bien se habían muerto o bien se la pasaban dentro de sus casas sin salir nunca a la calle" (Bolaño 34). Es justo sobre esta línea, sobre el papel de la mujer, en donde se debe agregar sobre la posición y organización de la ciudad con respecto a la pérdida de valores y rol social,

Dígase lo que se diga, son las que al final de la semana cuentan con un ingreso, llegan a los bailes con algo que se llama capacidad de pago [...], son las que en ciertos momentos del baile y la fiesta en el galerón se dan el lujo de escoger con qué tipo quieren bailar y salir y seguir. Los hombres habitan esa sociedad esperando cruzar la frontera y desempeñar el rol más heroico de ganar en dólares. Pero mientras eso no se logra, y eso no se logra fácilmente, los hombres se reúnen en los espacios públicos para tomar o jugar futbol y con mucha dificultad se encargan de los hijos y del hogar mientras la mujer, la hija o la hermana se encuentran en la faena (Gutiérrez 57). 
La voz narrativa del escritor chileno comunica desde el principio el colapso de la modernidad en la gran urbe y sus espacios a partir de la existencia de los iconos femeninos que no logran existir como quienes realmente son. El resultado es que ambas partes interactúan como patrones basados en "Futilidad, frivolidad e ironía. La sociedad más avanzada, la más ilustrada, la más preogresista, pierde tiempo rebuscando entre sus cimientos más ontológicos a un dios perdido, al que jamás podría aceptar aunque encontrase" (Wilber 358). De tal forma que dicha dimensión nos arroja una vertiente: la escritura del espacio y la ciudad como relato. Los laberintos y sus trampas que se ofrecen en las cuatro obras que abordamos, por otra parte, establecen una búsqueda de ser-ahí sin vigencia. Estas indagaciones en vez de encaminarse hacia posibles salidas sólo fecundan más historias, deslazamientos, destierros, exilios, movimientos, perdiciones, maldad, muerte y el discurso vacío que es silencio cuando nos enfrentamos a la opacidad del significante: la urbe.

El relato pone de manifiesto el desarrollo del vacío, fusión geométrica de la idea abstracta de la nada a manera de germen. De igual manera, como lugar en donde se produce la forma esférica para tornarse a la mujer en burbujas invertidas que no se completan y se desplazan a partir de círculos anteriores. Mientras que en 2666 los referentes provienen de la concepción urbana latinoamericana de lo moderno, una extensión en donde "ya no es exactamente humana, una dimensión excéntrica que corresponde a una despolarización del espacio y a una indiferenciación de las figuras del cuerpo" (Baudrillard 25). Aquí se clausura la madre que vimos en Los detectives salvajes, Amuleto y que transmutó en el tiempo cíclico de Putas asesinas; es el "entretiempo en patencia" en que el curso de la narración hace plausible que la acompañante precedente es desechada y surge el "ser-con", es decir, todos los otros protagonistas no pueden existir sin la existencia de una figura femenina.

El espacio narrativo se desgaja: la violencia y el mal está en potencia en el vacío. En Los detectives salvajes esta dimensión comienza a rebasarse, pero Bolaño desvía este espacio de inserción original, lo trasforma y lo constituye a su vez en los otros tres textos que simultáneamente analizamos; una dimensión como un movimiento de 
autofagia, un procedimiento que a su vez anuncia una nueva lectura, burbujas de "ser-en dos". En Amuleto, el presente, el pasado y el futuro se aletargan en una presentización. La voz profética de Auxilio lo advierte: "Sea lo que sea, algo pasa con el tiempo. Yo sé que algo pasa con el tiempo y no digamos con el espacio" (Bolaño 107). Auxilio colapsa con el presente, anuncia un año 2000 que no verá, en medio de un espacio narrativo que se derrumba en la cuarta planta de la Facultad de Filosofía y Letras, para sobresaturar el espacio que va realizando un progreso de la narración hacia una sobremodernidad, en donde a su vez se encubre de nuevo al vacío. Siguiendo la curva de los relatos encontramos que el espacio vacío surge a partir de la intimidad de las protagonistas, su deseo de "ser-ahí", de tener un papel fundamental en el mundo vivencia el rompimiento con el mismo espacio.

Los signos de dichas resquebrajaduras sociales sugieren que se está sufriendo un colapso en los espacios urbanos pues los valores antiguos y eternos colisionan con los actuales. Las mujeres bolañianas intentan restaurar o renacer de aquellos principios. Para Auxilio, heroína moderna, el presente es válido sólo en virtud de las potencialidades del futuro y en la medida en que el avance de la historia, en continuas metamorfosis, esta es vista como una revolución posmoderna: un camino hacia dicha dimensión bolañiana. En Amuleto, el yo es una ramificación que se va unificando como un proceso de decadencia y el desarrollo de las culturas de masas será una característica de la posmodernidad (Hutcheon 57), encubierta por el autor:

Así pues los muchachos fantasmas cruzaron el valle y se despeñaron en el abismo. Un tránsito breve. Y su canto fantasma o el eco de su canto fantasma, que es como decir el eco de la nada, siguió marchando al mismo paso que ellos, que era el paso del valor y de la generosidad, en mis oídos. Una canción apenas audible, un canto de guerra y de amor, porque los niños sin duda se dirigían hacia la guerra pero lo hacían recordando las actitudes teatrales y soberanas del amor. Y aunque el canto que escuché hablaba de la guerra, de las hazañas heroicas de una generación entera de jóvenes latinoamericanos sacrificados, yo supe que por encima de todo hablaba del valor y de los espejos, del deseo y del placer (Bolaño, Amuleto 154). 
En efecto, la ciudad y el espacio narrativo colapsan y evolucionan en Putas asesinas, su lectura es la comprensión espacio-temporal y el principio del posmodernismo como decadencia social. Las habitantes envuelven climáticamente el espacio, la atmosfera y son el objeto de estadio del yo para pensar la preocupación contemporánea. Las tendencias del pensamiento sobre el espacio de la mujer permiten reconocer que no se ha evolucionado para mejorar y que el mal sigue siendo compartido por todos dentro de la cultura globalizada. En un sentido espacial, la culturización de la mujer en el futuro participaría en la necesidad por producir lugares exteriores que le sean posibles de vivir. Space conditioning se coloca como el tema espacialnarratológico en el período que Bolaño advierte. Al mismo tiempo, se hilvana la experiencia urbana de esas ciudades que se desarrollan arquitectónicamente mientras las urbanitas trastocan el espectáculo de la nada. Si en 2666, la mujer en la ciudad es la protagonista debajo de la gran burbuja que produce la búsqueda de Benno von Archimboldi, la espumidificación de la frontera (Sloterdijk, Esferas III... 472), será la trinchera de la pobreza latina, toda la geometría que conforman a la obra se entrelaza, presenta a la muerte y la posmodernidad de la mano.

Las protagonistas comienzan viajes hacia espacios en los que pretenden recrear un cierto objetivo pero que de igual forma son lugares áridos e improductivos. Su intimidad ha de ocuparse, en primer término, de las demandas de su espacio en el mundo contemporáneo. La urbe y el capitalismo gore son georreferenciaciones fronterizas, a modo de tópicos que representan una consistencia de bipolaridad desplegada, espacio de unicidad dual, pues "el concepto de transfeminismo entendido como una articulación tanto del pensamiento como de resistencia social que es capaz de conservar como necesarios ciertos supuestos de la lucha feminista para la obtención de derechos en ciertos espacios geopolíticamente diversos" (Valencia 178). Empleamos tales conceptos, ciudad, espacio, mujer, y transfeminismos, puesto que en la narrativa bolañiana las diferentes locuciones sobre los territorios contienen una característica básica y una especie de construcción que diseñará la urbe posmoderna en donde la liberación sexual y cultural de la mujer en la segunda mitad del siglo XX, no le deparó una habitación 
propia, sino una forma desterritorializada con alta violencia física, el cuerpo es visto como una producción de riqueza, entre el fenómeno social y el poder económico tal como se consuma discursivamente en 2666. Bolaño continua detallando a un "Feminismo de libre mercado que ha hecho suyas las demandas de vigilancia y represión del biopoder y exige que se apliquen (censura, castigo, criminalización...) en nombre y para protección de las mujeres" (Valencia 179). Y, en efecto, fuimos creados desde una vida interior por la falta de una nueva complementación, no obstante, la posición espacial de la figura femenina es la atención particular en la exploración de la escritura, pues en ella se produce concretamente la configuración bolañiana bajo un valor descriptivo ideológico, de abrazar el vacío (asociado desde el Capitalismo), y el exterior: arqueología del no-ser. Nos absorbe la enorme esfera de la ciudad, tópico que opera a manera de contexto determinado, opresor de la identidad y de la libertad. Las cuatro obras aquí expuestas son piezas de un todo, de una audaz identificación entre el espacio y la unión diádica mujer-cuerpo durante el capitalismo.

Si Bourdieu sostuvo que el capitalismo estaba basado en un sistema patriarcal fomentado por una competencia entre la hombría para la legitimización de dicho sistema económico y social (64), en Bolaño el capitalismo es el conocimiento del futuro, su mayor alegato, lo que ata lo real con lo irracional; el pensamiento de la fragilidad en el espacio. La efigie femenina es geómetra que cae en el abismo de la urbe. Sin más. Bolaño propone representaciones de dar continuidad por otras vías a los discursos. Así, el espacio vale a manera de la figuración del vacío que transforma a la ciudad, pero desde la esfera iniciática, con el rompimiento que se rompe una y otra vez, la mujer. 


\section{Referencias}

Anderson, Perry. Los orígenes de la posmodernidad. Barcelona: Anagrama, 2000. Impreso.

Bachelard, Gaston. La poética del espacio. México: Fondo de Cultura Económica, 2000. Impreso.

Baudrillard, Jean. La transparencia del mal. Barcelona: Anagrama, 1991. Impreso.

Bolaño, Roberto. Llamadas telefónicas. Barcelona: Anagrama, 1997. Impreso.

Bolaño, Roberto. Los detectives salvajes. Barcelona: Anagrama, 1998. Impreso.

Bolaño, Roberto. Amuleto. Barcelona: Anagrama, 1999. Impreso.

Bolaño, Roberto. Putas asesinas. Barcelona: Anagrama, 2001. Impreso.

Bolaño, Roberto. 2666. Barcelona: Anagrama, 2004. Impreso.

Bourdieu, Pierre. La dominación masculina. Anagrama, Barcelona: Anagrama, 2000. Impreso.

Del Pino, Mateo y Gregorio Rodríguez Herrera. Metáforas de perversidad, percepción y representación de lo femenino en el ámbito literario $y$ artístico. Universidad de Chile, 2004: 145. Impreso.

Estrada, María de la Luz. Observatorio Nacional de Feminicidio. https://www. observatoriofeminicidiomexico.org/, 2019. Digital.

Graves, Robert. La diosa blanca. Gramática Histórica del Mito Poético. Madrid: Alianza, 1994. Impreso.

Gutiérrez Zermeño, Griselda. Violencia sexista: algunas claves para la comprensión del feminicidio en Ciudad Juárez. México: Universidad Nacional Autónoma de México, Programa Universitario de Estudios de Género, 2004: 57. Digital.

Hobsbawm, Eric. Historia del siglo XX. Barcelona: Crítica, 1998. Impreso.

Howard Gass, William. Fiction and the figures of Life. Boston: David R. Godine Publisher, 1970. Digital.

Hutcheon, Linda. A Poetics of Postmodernism: The Teachings of TwentiethCentury Art Forms. Londres: Methuen, 1985. Impreso.

Lipovetsky, Gilles. La era del vacío. Ensayos sobre el individualismo contemporáneo. Barcelona: Anagrama, 1986. Impreso.

Lipovetsky, Gilles. La tercera mujer. Barcelona: Anagrama, 2006. Impreso.

Nam Choi, Myung. La mujer en la novela policial: evolución de la protagonista femenina en cinco autoras hispanas. Estados Unidos de Norteamérica: Palibrio, 2012. Digital.

Picatto, Pablo. "La era dorada de la novela policiaca”. Nexos (2015). Digital.

Signorelli, Amalia. Antropología urbana. México: Universidad Autónoma Metropolitana, 1999. Impreso. 
Sloterdijk, Peter. Esferas I: Burbujas. Microsferología; (trad. Isidoro Reguera, prol. Rüdiger Safranski). Madrid: Siruela, 2003. Impreso.

Sloterdijk, Peter. Esferas III: Espumas. Esferología plural, (trad. Isidoro Reguera, prol. Rüdiger Safranski). Madrid: Siruela, 2006. Impreso.

Soazo Ahumada, Christian Andrés. Una historia salvaje: re-versión de la modernidad, vanguardia y globalización en la obra de Roberto Bolaño. Philologischen Fakultä der Albert-Ludwigs-Universität Freiburg i. Br. 2012: 231. Impreso.

Valencia, Sayak. Capitalismo gore. España: Editorial Melusina, 2010. Impreso. Waugh, Patricia. Metafiction. The Theory and Practice of Self-Conscious Fiction. London: Routledge, 1984. Impreso.

Wilber, Ken. Breve historia de todas las cosas. España: Kairós, 1996. Impreso. 